\title{
Reisewarnung wegen Zika-Viren
}

\author{
Wegen der Gefahr einer durch Stechmücken übertragenen Zika-Virus-Infektion rät die \\ Deutsche Gesellschaft für Tropenmedizin Schwangeren derzeit von Reisen nach Brasilien ab. \\ Prof. Dr. Dr. Jonas Schmidt-Chanasit vom Bernhard-Nocht-Institut für Tropenmedizin \\ zu den Hintergründen.
}

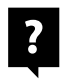

Prof. Dr. Dr. Jonas Schmidt-Chanasit Bernhard-Nocht-Institut für Tropenmedizin, Hamburg

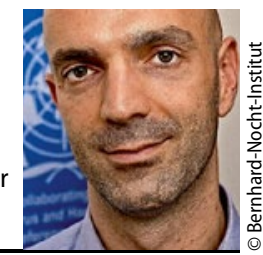

MMW: Was weiß man über die Risiken einer Zika-Virus-Infektion in der Schwangerschaft?

Schmidt-Chanasit: Vieles deutet darauf hin, dass es einen Zusammenhang gibt zwischen einer Zika-Virus-Infektion in der Schwangerschaft, höchstwahrscheinlich im ersten oder zweiten Trimenon, und einer Mikrozephalie beim ungeborenen Kind. Sowohl in Brasilien als auch in Französisch-Polynesien gibt es diese Koinzidenz, und gleichzeitig sind keine Hinweise auf andere Erreger oder Toxine bekannt, die diese Missbildungen hervorgerufen haben könnten. Insofern ist der Zusammenhang wahrscheinlich, der endgültige Beweis steht aber noch aus. Wir sind deswegen auf Nummer sicher gegangen und raten Schwangeren und Frauen, die schwanger werden wollen, Gebiete mit hohem Infektionsdruck $\mathrm{zu}$ vermeiden. Da sich die Zika-VirusEpidemie momentan sehr rasch ausweitet, sollten die Frauen eine reisemedizinische Beratung in Anspruch nehmen.

MMW: In Europa wurden ZikaVirus-Infektionen bisher nur bei Reiserückkehrern festgestellt. Wann sollte man daran denken?
Schmidt-Chanasit: Abgesehen von schweren Verläufen, die mit einer ZikaVirus-Infektion einhergehen können, wie einem Guillain-Barré-Syndrom oder anderen neurologischen Schädigungen, ist die Erkrankung meistens asymptomatisch bzw. geht mit einer schwachen und eher unspezifischen Symptomatik einher wie Fieber, Hautausschlag oder Muskelschmerzen. Damit ist sie klinisch nicht zu unterscheiden von Infektionen mit Chikungunya- oder Dengue-Virus oder einer normalen Sommergrippe. Hier kann man nur einen Verdacht äußern, der darauf basiert, dass sich die Person in einer Region aufgehalten hat, in der das Virus gerade zirkuliert. Die Diagnose kann nur über das Labor erfolgen. Wichtig ist, außer Blut- auch Urinproben einzuschicken, weil das Virus dort länger nachweisbar ist.

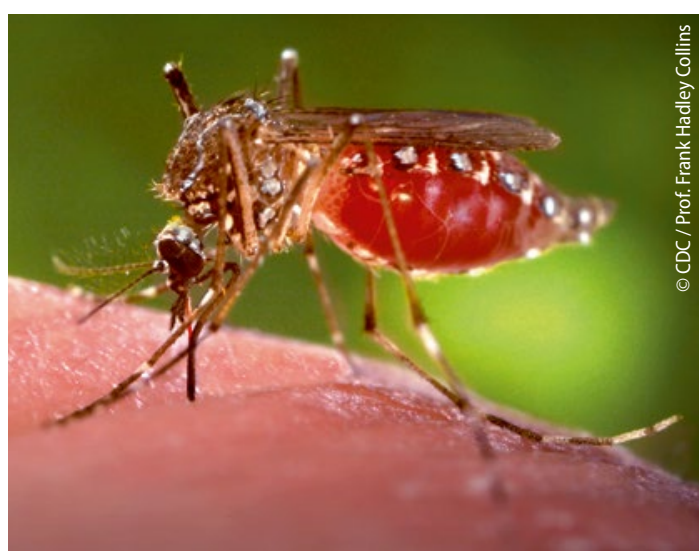

Aedes-Mücke bei der Blutmahlzeit: Die Zika-VirusÜberträger sind tag- und dämmerungsaktiv.

MMW: Wie kommt es plötzlich zu dem massiven Auftreten von ZikaVirus-Infektionen in Südamerika?
Schmidt-Chanasit: Es ist typisch für Arboviren, dass sie von heute auf morgen massive Ausbrüche hervorrufen. Sie kommen wie aus dem Nichts und verschwinden auch wieder ins Nichts: Wenn sich eine Herdenimmunität ausgebildet hat, bricht die Epidemie in sich zusammen und es gibt eine stille Zirkulation mit wenigen Fällen. Bei den Ursachen spielen Hunderte von Faktoren eine Rolle, die wir nicht kennen, von der Immunität bis hin zu klimatischen Variablen.

\section{MMW: Könnten Zika-Viren auch in Europa heimisch werden?}

Schmidt-Chanasit: Rein theoretisch ist das möglich. Die Übertragung erfolgt vermutlich über Gelbfieber- und Tigermücken. Die Tigermücke gibt es auch in Europa. Im Süden von Italien, Spanien und Portugal könnte das also passieren. In Deutschland kommt die Tigermücke auch vor, z. B. in Freiburg, Heidelberg oder Bayern. Aber hier würde der Winter einem Ausbruch ein Ende setzen.

MMW: Was ist Ihre Prognose für die aktuelle Epidemie?

Schmidt-Chanasit: Meine Prognose ist, dass sich die Zika-Viren weiter nach Mexiko und in die USA ausbreiten. Das Drängendste ist jetzt, den Zusammenhang mit der Mikrozephalie zu klären. Die Zahlen sind erschreckend - ein 20-facher Anstieg allein in Brasilien. Man muss, so schnell es geht, an einem Impfstoff arbeiten.

Interview: Dr. Beate Schumacher 